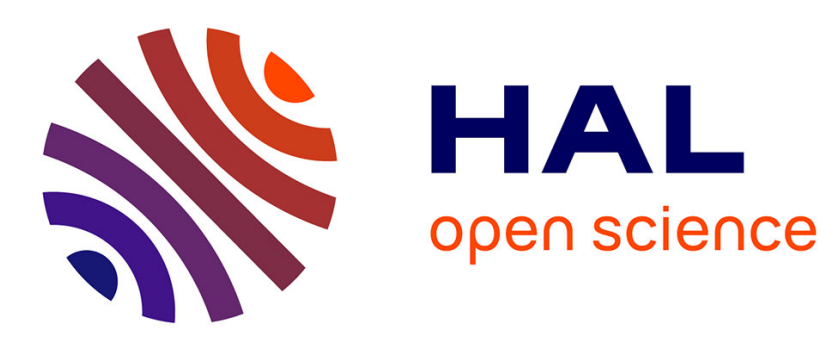

\title{
Two Cases of Study for Control Reconfiguration of Discrete Event Systems (DES)
}

\author{
Imane Tahiri, A. Philippot, V. Carre-Menetrier, Abdelouahed Tajer
}

\section{To cite this version:}

Imane Tahiri, A. Philippot, V. Carre-Menetrier, Abdelouahed Tajer. Two Cases of Study for Control Reconfiguration of Discrete Event Systems (DES). International Conference on Informatics in Control, Automation and Robotics (ICINCO), 2019, Prague, Czech Republic. 10.5220/0007977301200129 . hal-02336449

\section{HAL Id: hal-02336449 \\ https://hal.science/hal-02336449}

Submitted on 28 Oct 2019

HAL is a multi-disciplinary open access archive for the deposit and dissemination of scientific research documents, whether they are published or not. The documents may come from teaching and research institutions in France or abroad, or from public or private research centers.
L'archive ouverte pluridisciplinaire HAL, est destinée au dépôt et à la diffusion de documents scientifiques de niveau recherche, publiés ou non, émanant des établissements d'enseignement et de recherche français ou étrangers, des laboratoires publics ou privés. 


\title{
Two Cases of Study for Control Reconfiguration of Discrete Event Systems (DES)
}

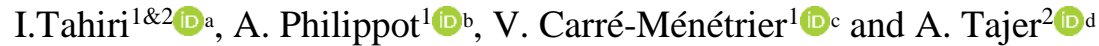 \\ ${ }^{I}$ Research Centre in Information and Communication and Technology (CReSTIC), URCA University, Reims, France \\ ${ }^{2}$ Electrical Engineering and Systems Control Laboratory (LGeCOS), UCA University, Marrakech, Morocco \\ \{Imane.tahiri, alexandre.philippot, veronique.carre\}@univ-reims.fr, a.tajer@uca.ma
}

Keywords: Control reconfiguration, Supervisory control theory, centralized control, distributed control, discrete event systems, timed discrete event systems, sensor faults detection, manufacturing systems.

\begin{abstract}
In this paper, we propose two cases of study for control reconfiguration of Discrete Event Systems. The main contributions are based on a safe centralized and distributed control synthesis founded on timed properties. In fact, if a sensor fault is detected, the controller of the normal behavior is reconfigured to a timed controller where the timed information replaces the information lost on the faulty sensor. Finally, we apply our contribution to a manufacturing system to illustrate our results and compare between the two frameworks.
\end{abstract}

\section{INTRODUCTION}

Nowadays, Manufacturing Systems (MS) are subject to strong constraints induced by an uncertain environment, changing and dominated by strong international competition. This environment implies that an MS is increasingly oriented towards a large diversification of products manufactured in small and medium series and not only towards a single type of product.

The impact of this change in industry is reflected by the need to have systems that can be able to adapt to the production changes, to be flexible (Bordoloi, Cooper, and Matsuo 1999), (Terkaj, Tolio, and Valente 2009) and robust in order to meet the diversity, the productivity (Rawat, Gupta, and Juneja 2018), the quality, the optimization of operating costs and, finally, the reduction of failures risks requests.

The respect of these constraints, which are becoming more demanding, has led to a revolution in the manufacturing field. This is manifested by the increasing massive use of powerful information systems, especially, the increasing automation of workshops and processes.

MS automation increases the productivity and the competitiveness of compagnies engaged in the manufactured goods production. Therefore, it is an important economic issue. This automation requires the development of methodologies including all the system life cycle phases, from specification to operation, in order to insure a safe operating context (Reniers 2017), (Tuptuk and Hailes 2018).

However, given the different parameters to be considered in an MS, the latter becomes very complex (Kul'ba et al. 2016). This complexity concerns both the monitoring / supervision as well as the control part.

The Reconfigurable Manufacturing System (RMS) concept invented by the University of Michigan in 1999 (Y. Koren et al. 1999), is considered as a new solution to gain competitiveness and meet the requests of a constantly changing market. In fact, designing an MS that can be reconfigured (Yoram Koren and Shpitalni 2010) accurately, quickly, and inexpensively according to a market change offers a significant economic benefit to manufacturing compagnies. The goal of an RMS is to design systems with machines and controllers that can meet the minimum cost and the new market requirements that are characterized by diverse and responsive needs. RMS also aim to adapt to changes in both internal and external environments that companies face.

https://orcid.org/0000-0003-2203-2604

b(D) https://orcid.org/0000-0001-5229-9452

c(D) https://orcid.org/0000-0002-9576-9108

d(D) https://orcid.org/0000-0002-1528-7855 
The reconfiguration process is a reorganization process of the system hardware and / or software. The objective of this reorganization is to be able to ensure the production by making a compromise between the objectives of production and the state of the system. This reconfiguration process can be triggered by two categories of events related to either products or production resources.

A production change can be related to the production nature, the quality or the quantity of products. Indeed, in the manufacturing industry, Flexible Manufacturing Systems (FMS) have been designed to respond to the production of small or medium series of products. This means that it may be necessary on a given production horizon to start manufacturing products that have not been scheduled. This is only possible if the resources involved in production do not operate at full load or if new production resources can be committed. A change in production can also be related to the quality of the products. The requirement of a higher quality compared to the one initially planned may require the commitment of transformational resources able of obtaining it. It is the same principle for the quantity whose requirements may vary during production.

Overall, these changes may lead to an addition or removal of certain hardware resources related to the set of those engaged in the current production.

On the other hand, a production resource state change is characterized by two major events: failures and repairs. In case of failures, the reconfiguration process must first look for substituting the faulty resource with another one. The goal in this context is to use active or passive redundancies to recover the failure. The two types of events that may trigger a reconfiguration process are not necessarily decoupled. In fact, a faulty resource can lead to a change of production due to the impossibility of finding the necessary production capacities in the required time.

A reconfiguration process implementation depends on two parameters: the trigger event and time constraints exercising on the system when this event occurs. Two complementary situations can be considered: the case of a new production lunching when the system is in a stop situation and the case of a failure occurrence on a running system.

Most of solutions proposed in the research works as well as the practice ones are based on a material redundancy to fill the failure of a system component. Considering the technological development of the components of manufacturing systems and their complexity, this solution proves to be very expensive.

Therefore, in this work, we are interested to design a reconfigurable control based on a timed information of a special class of MS: Discrete Event Systems (DES). A DES (Cassandras and Lafortune 2008) is a dynamic system whose state space is discrete. Its evolution is governed by the occurrence of discrete events. These physical events cause a change in the state of the system.

The main idea is to design a reconfigurable control able to adapt and exploit the services still available offered by the system plant in case of a sensor fault detection.

The reconfiguration process here consists on leading the MS from its current state (CS) in the normal behavior controller where the fault is detected, thanks to the diagnosis, to a target state (TS) in a faulty behavior controller in order to maintain the MS functioning despite faults. The information lost about a faulty sensor is replaced by a so-called time-based estimator of its functioning (Tahiri et al. 2019).

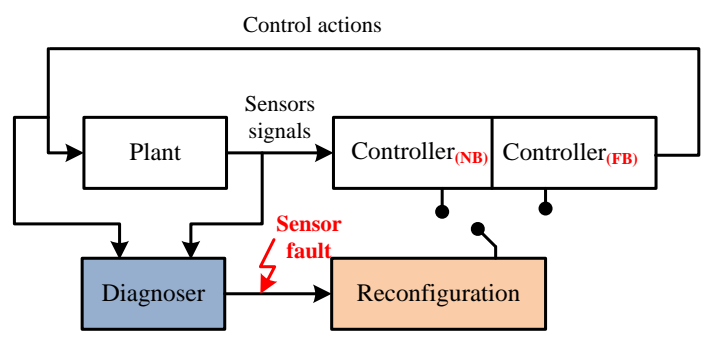

Figure 1 : Control reconfiguration loop

The control reconfiguration loop (figure 1) is based on three elements: (1) The Supervisory Control Theory principle (SCT) initiated by Ramadge and Wonham (R\&W) in (Ramadge and Wonham 1989). The SCT aims at synthesizing a supervisor which ensures that the behavior of a plant remains acceptable against the specifications. (2) The diagnoser bloc that aims to detect and isolate faults. Diagnosis is not the aim of this paper, some related research works are given in (A. Philippot and Carré-Ménétrier 2011), (Blanke et al. 2016), (Hélouët et al. 2014). In this work we treat the case of unobservable sensor faults that are defined by a stuck-on/off of a sensor. (3) and finally, the reconfiguration bloc which consists on taking decision to switch from a normal behavior controller to a faulty one.

This paper is organized as follows: two cases for control reconfiguration of DES are introduced in section 2. The first case is based on a centralized control while the second one is founded on a distributed control. In section 3, we illustrate our results around a manufacturing system in addition to a discussion on the application results. Finally, in section 5, a conclusion of our presented work is reported. 


\section{PROPOSED APPROACHES}

\subsection{Centralized control reconfiguration of MS}

The first new framework proposed in this paper is a centralized control reconfiguration of DES. The method is based on defining two separate models of the system plant. The first one describes the normal behavior of the system and the second model describes its faulty behavior where a timed information replaces each faulty sensor through a time-based estimator (Tahiri et al. 2019). This, in order to determine a centralized controller that manages the two system' behaviors as well as the switch between them (figure 2).

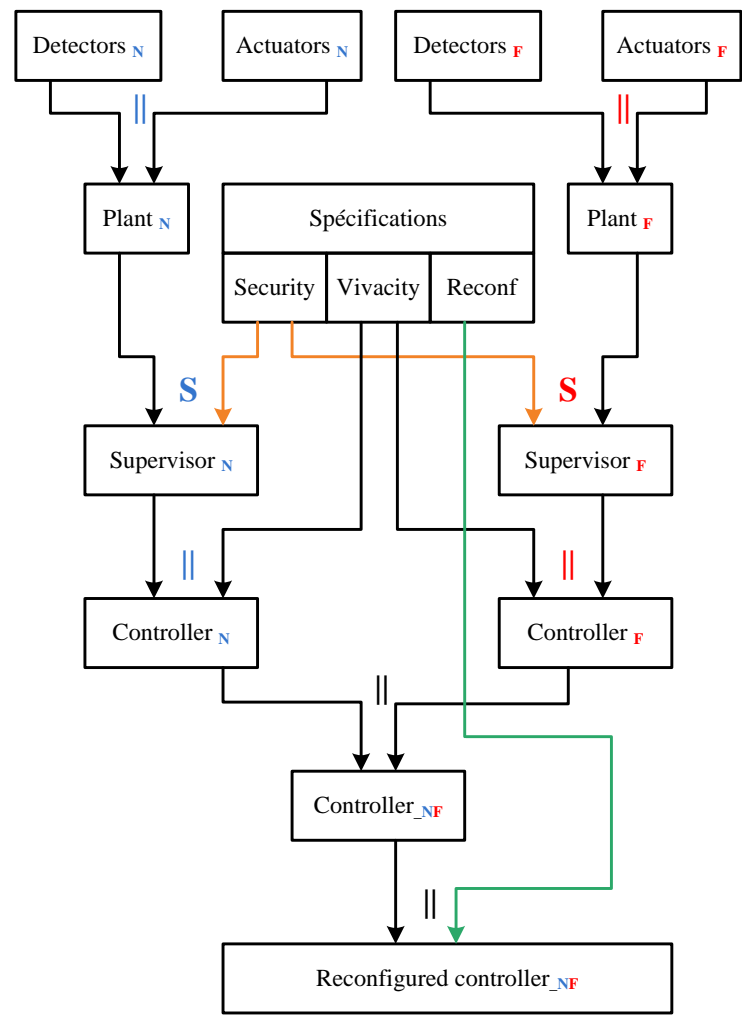

Figure 2 : Centralized control reconfiguration framework

\subsubsection{Defining the plant_N and plant_F models}

Defining the plant normal behavior model (plant_N) is based on the practical model presented in (Alexandre Philippot 2006). The main idea of this practical model consists on devising the MS into several plant elements (PE) and then defining a detectors model (detectors_N) that describes the normal behavior of all detectors constituting the system's PE, and an actuators model (actuators_N) that describes the normal behavior of each actuator of the MS with its associated detectors. The plant model is given by the synchronization of these two models. Formally, the "plant_N" model is defined by the following automaton:

$A \_N=\left(Q \_N, \Sigma \_N, \delta \_N, q_{0 \_N}, Q Q_{m} \_\right.$) such as:

- $Q_{-}$is a finite set of all states of $A_{-}$.

- $\Sigma \_\mathrm{N}$ is the set of events

- $\delta \_\mathrm{N}$ is the transition function. A transition is defined by: $\delta \_\mathrm{N}\left(\mathrm{q} \_\mathrm{N}, \sigma\right)=\mathrm{q}{ }^{\prime} \mathrm{N}$. $\sigma$ is the occurrence of an event of $\Sigma_{-}$. .

- $\mathrm{q}_{0 \_\mathrm{N}}$ is the initial state of the automaton $\mathrm{A} \_\mathrm{N}$, such that $\mathrm{q}_{0 \_\mathrm{N}} \in \mathrm{Q} \_\mathrm{N}$.

- $\mathrm{Q}_{\mathrm{m} \_\mathrm{N}}$ is the set of marked states in $\mathrm{A}_{-\mathrm{N}}$, such that $\mathrm{Q}_{\mathrm{m} \_\mathrm{N}} \subseteq \mathrm{Q} \_\mathrm{N}$.

The model presented above does not take into account timed events which are the principle of the faulty model. Therefore, determining the plant faulty behavior model (plant_F) is based on an extension of the practical model presented in (Alexandre Philippot 2006) where timed events are added. In a previous work (Tahiri et al. 2019), we discussed a method to include time to DES, we talk about Timed Discrete Event Systems (TDES). A method where time is presented through a clock and considered as an event, which makes the modelling phase by Finite State Machines (FSM) a simple task. In fact, the faulty behavior (plant_F) or time-based estimator guaranties the same normal behavior due to the replacement of faulty sensors through the clocks that insure their functioning. The "plant_F" model is given by the synchronization of the two-timed detectors model (detectors_F) and actuators model (actuators_F). Formally, the "plant_F" model is defined by the following automaton:

$A \_F=\left(Q \_F, \Sigma \_F, \delta \_F, q 0 \_F, Q\right.$ Q $\left.\_F\right)$ such as:

- Q_F is a finite set of all states of A_F.

- $\Sigma_{-} \mathrm{F}$ is the set of events, such as $\Sigma_{-\mathrm{F}}=\Sigma_{\mathrm{nT}} \cup \Sigma_{\mathrm{T}}$. With: $\Sigma_{\mathrm{nT}}$ is the set of non-timed events and $\Sigma_{\mathrm{T}}$ is the set of timed events such as: $\Sigma_{\mathrm{T}}=\mathrm{C} \cup \mathrm{D}$ with:

$\mathrm{C}$ : Set of clocks, each clock is defined by an activation and deactivation $\mathrm{C}=\uparrow \mathrm{ck}_{\mathrm{i}} \cup \downarrow \mathrm{ck}_{\mathrm{i}}$

D: Finite set of durations di associated to each clock ck $\mathrm{i}_{\mathrm{i}}$, such as $\mathrm{D}=\left\{\mathrm{d}_{1}, \mathrm{~d}_{2}, \ldots, \mathrm{d}_{\mathrm{i}}\right\}$.

- $\delta \_F$ is the transition function. A transition is defined by: $\delta_{-} \mathrm{F}\left(\mathrm{q} \_\mathrm{F}, \sigma\right)=\mathrm{q}^{\prime} \_\mathrm{F} . \sigma$ is the occurrence of a timed event or not of $\Sigma$.

- $\mathrm{q}_{0 \_\mathrm{F}}$ is the initial state of the automaton $\mathrm{A} \_\mathrm{F}$, such that $\mathrm{q}_{0 \_} \mathrm{F} \in \mathrm{Q} \_\mathrm{F}$.

- $\mathrm{Q}_{\mathrm{m} \_\mathrm{F}}$ is the set of marked states in A_F, such that $\mathrm{Q}_{\mathrm{m} \_\mathrm{F}} \subseteq \mathrm{Q} \_\mathrm{F}$. 


\subsubsection{Defining Specifications}

After having constituted the plant models of the process, it is necessary to be able to integrate the specifications information through a model of specifications. It is the second step to achieve a centralized control reconfiguration. The controller establishes its specificities and represents the behavior of normal operations of the process and expresses safety constraints, what we must not do, and liveness, what we must do, on the process.

Integrating the specifications constraints consists of inhibiting actions and / or arranging and sequencing the execution of orders sent to the MS. A constraint cannot cause additional actions in a model but may express a restriction, or inhibition, of those actions. The modelling of these constraints can be carried out either by automatons or by logical equations. The constraints can be applied either globally to the whole process, or locally to each PE. Our approach is based on obtaining a centralized structure. Therefore, we apply both local and global constraints modelled by FSM on the plant.

Each defined safety and/or liveness specification on the normal behavior, its corresponding specification in faulty behavior is determined too by replacing the event associated to the sensor by its corresponding clock.

The reconfiguration specifications are defined as the constraints that allow the switch from a normal behavior to the faulty (timed) one when a faulty event is detected. We define an automaton for each faulty event. Afterward, all automata are synchronized to obtain the automaton presenting the reconfiguration constraints of the MS.

\subsubsection{Defining supervisors, controllers and reconfigured controller}

The supervisor_N (resp supervisor_F) is obtained by synthesising the "plant_N" model (resp plant_F) with its associated safety specifications. This step aims at synthesizing a correct supervisor by construction, which ensures that the behavior of a system remains admissible compared to its specifications.

We note that the synchronisation and/or the synthesis in this work are applied through the SUPREMICA software (Akesson et al. 2006).

The fourth step is to determine controllers. The controller_N (resp controller_F) is obtained through a synchronization of the supervisor_ $\mathrm{N}$ model (resp supervisor_F) with its associated liveness specification. Th resulting model describes the desired behavior of the MS by the operator.

The supervisor should not be confused with the controller. A supervisor here is a theoretical object, which can inhibit, prohibit actions only and does not take the initiative to trigger them. Thus, the supervisor is not directly implementable. Contrariwise, the controller allows both authorizing and prohibiting actions and can be directly implemented.

Afterwards, to achieve a centralized control, the two controller models "controller_N" and "controller_F" are synchronized to obtain a global model "controller_NF" which manages both normal and faulty behaviors.

To make the controller_NF able of switching between the two behaviors if a sensor fault is detected, the reconfiguration specifications are added. Therefore, a synchronization of the "controller_NF" model with the reconfiguration specification is needed. The resulting centralized controller is called "reconfigured controller_NF".

\subsection{Distributed control reconfiguration of MS}

The idea behind proposing a second approach is the fact that the first one discussed above presents a major disadvantage which is the combinatorial explosion. Indeed, studying complex MS under a centralized control is a complicated task to perform. Hence, it is necessary to study the control reconfiguration with a distributed architecture view.

The proposed framework for the distributed control reconfiguration is presented by figure 3 . It is based in a first step on modelling the MS plant under several plant elements. Then, two sets of specifications are defined: local and global ones. These specifications are integrated in several stages of the control design in order to define the MS different supervisors and both local and distributed controllers. For each PE, two distributed controllers are determined for normal and faulty behavior. For a PLC implementation purpose, the distributed controllers are interpreted into a IEC61131-3 PLC programming language (SFC Sequential Function Chart language based on IEC60848 Grafcet tool). Finally, the switch between the two controllers is assured by the reconfiguration specifications which are translated to Grafcet too.

\subsubsection{Defining the $P E \_N$ and $P E \_F$ models}

Defining the two models of normal $\left(\mathrm{PE} \_\mathrm{N}\right)$ and faulty $\left(\mathrm{PE} \_\mathrm{F}\right)$ behaviors of each $\mathrm{PE}$ of the MS is based on the same modelling principle evoked in section 
1

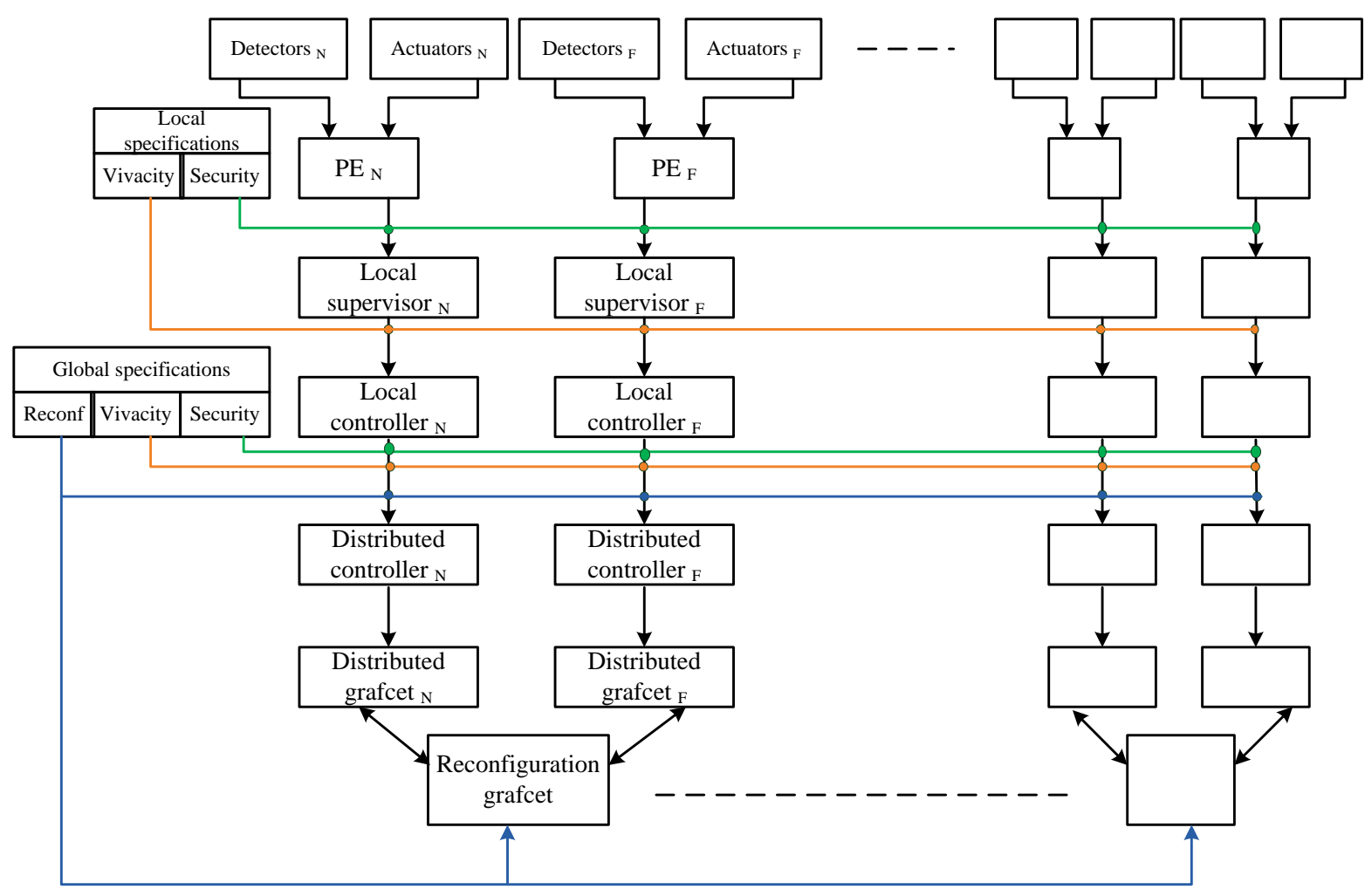

Figure 3 : Distributed control reconfiguration framework
(2.1.1). Contrariwise, in this framework, we keep the different practical models of each PE and we do not synchronize them in order to achieve a distributed control reconfiguration.

Let $\mathrm{G}$ denotes the set of PE models such as: $\mathrm{G}=\mathrm{G} \_\mathrm{N} \cup \mathrm{G} \_\mathrm{F}$ with: And

$G_{-N}=\bigcup_{i=1}^{n} A_{-N}$ set of normal PE behaviors.

$G_{-F}=\bigcup_{i=1}^{n} A_{-F}$ set of faulty PE behaviors. $\mathrm{n}$ : is the number of PE constituting the MS.

\subsubsection{Defining Specifications}

To avoid the combinatorial explosion related to the method proposed before in this paper, a specification modelling method is proposed to overcome this problem. Both local and global specifications are presented by Boolean equations.

A local specification can be defined by a logical implication as given by the formula below:

$$
x \cdot y=0 \text { (eq1) }
$$

Such as " $x$ " is a state of G state's set and " $y$ " is a controllable event. The implication above means that if $x$ is true then $y$ is forbidden.
A global specification of liveness or safety is defined by a logical implication as given by the expression below:

$$
\text { If } \mathrm{c} \text { then }\{y=0 \text { else } y=1\} \quad \text { (eq2) }
$$

Following the verification of the condition " $c$ " if it is true or not, the action " $y$ " can be authorized $(y=1)$ or inhibited $(y=0)$.

A condition " $c$ " can belong to three different categories (Qamsane, Tajer, and Philippot 2016): A simple condition using Boolean variables or functions, a composed condition using a sequence of Boolean variables or functions that precede each other, and a combined condition containing simple and composed conditions such as: $c \in \uparrow \downarrow e_{i}$ and/or $c \in \uparrow \downarrow d_{i}$.

Whereas, a reconfiguration specification (RS) is defined by logical equations as follows:

$$
\begin{aligned}
& R S: \text { If } X_{i} \text { and } f_{s}=1 \text { Then } \\
& \left(F: \mathrm{G}_{(\mathrm{F})}^{*}\left\{X_{j i}\right\}\right) \text { and }\left(F: \mathrm{G}_{(\mathrm{N})}^{*}\{\}\right) \\
& \text { Else If } X_{j i} \text { and } f_{s}=0 \text { Then } \\
& \left(F: \mathrm{G}_{(\mathrm{N})}^{*}\left\{X_{i}\right\}\right) \text { and }\left(F: \mathrm{G}_{(\mathrm{F})}^{*}\{\}\right)
\end{aligned}
$$

Such as $\mathrm{G}_{(\mathrm{N})}^{*}$ is the grafcet associated to the normal distributed controller and $\mathrm{G}_{(\mathrm{F})}^{*}$ is the grafcet associated to the faulty distributed controller. 
With $X_{i}$ is the Boolean variable associated to the step "i" of $\mathrm{G}_{(F)}^{*}$ and $X_{j i}$ its corresponding variable associated to the step " $\mathrm{ji}$ " in $\mathrm{G}_{(\mathrm{N})}^{*}$. The expression above means that if $X_{i}$ is active and a sensor fault is detected, a switch to the faulty mode is requested by forcing its grafcet $\mathrm{G}_{(F)}^{*}$ to start from the step $X_{j i}$ and deactivating the normal mode grafcet $\mathrm{G}_{(\mathrm{N})}^{*}$.

\subsubsection{Defining supervisors, controllers and reconfigured controller}

\subsubsection{Local synthesis control}

In a previous work (Tahiri et al. 2018), we proposed a new framework in order to achieve a control synthesis. The approach is based on an extension of the PE models. This extension is generated by SUPREMICA software (Akesson et al. 2006) through an Extended Finite State Machine (EFSM) that contains guards, variables and actions that can facilitate a compact representation of a large and complex DES unlike FSM. The resulting automaton is noted $\left\{\left(\mathrm{A} \_\mathrm{N}\right)\right.$ curr $\}$ for normal behavior and $\left\{\left(\mathrm{A} \_\mathrm{F}\right)\right.$ curr $\}$ for faulty behavior.

To obtain the several local controllers for each $\mathrm{PE}$, we apply the synthesis of supervisory control using SUPREMICA software between the $\left\{\left(\mathrm{A} \_\mathrm{N}\right)\right.$ curr $\}$ or $\left\{\left(\mathrm{A} \_\mathrm{F}\right)\right.$ curr $\}$ models and the automaton presenting the local specifications.

The local specification equation given in section (2.2.2) is presented by an EFSM as shown in figure 4 .

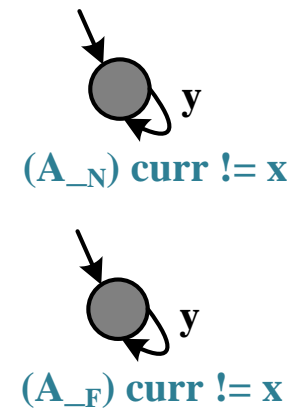

Figure 4 : Local specifications modelling

Each specification is composed of a single state and a self-loop transition associated to the controllable event " $y$ " and the guard expressed by $\left\{\left(\mathrm{A} \_\mathrm{N}\right)\right.$ curr != $\mathrm{x}\}$ or $\left\{\left(\mathrm{A} \_\mathrm{F}\right)\right.$ curr $\left.!=\mathrm{x}\right\}$, which means if the current state of $\left(A \_N\right)$ or $\left(A \_F\right)$ is different from " $x$ " then " $y$ " is allowed.

The resulting automata of the control synthesis are the local controllers of each PE and both normal and faulty behaviors.

\subsubsection{Global synthesis control}

An MS running often evokes the synchronism and parallelism between its different PE. Thereby, a PE may depend on another one to guarantee the desired behavior. Therefore, a communication between several PE is necessary. To achieve that, a global control synthesis is needed to obtain distributed controllers of normal behavior and faulty one for each PE.

This synthesis consists first in aggregating the local controllers as follows:

The untimed controllable events are merged into macro-states. The states reached by controllable events are associated in macro-states linked by uncontrollable events (detectors events) or by timed events $\left\{\uparrow \mathrm{ck}_{\mathrm{i}}\right.$, $\left.\downarrow \mathrm{ck}_{\mathrm{i}}, \mathrm{d}_{\mathrm{i}}\right\}$. If the local controller's state is associated to a rising edge of a controllable event, then the order is authorized and belongs to the $\mathrm{Ord}$ set. If it is associated to a falling edge of this event, then the order is inhibited and belongs to the Inh set

The timed events $\uparrow \downarrow c k$ are merged in macro-states linked by uncontrollable events and timed events " $\mathrm{d}$ ". If the state of the timed local aggregated controller by the first aggregation reached by an event corresponding to the clock' activation, then this event belongs to a set noted $\mathrm{A}_{\text {ск. }}$. If it is reached by an event corresponding to the clock' deactivation, then this event belongs to a set noted $\mathrm{D}_{\mathrm{ck}}$. The self-loop transition will be the transition that links the two macro-states that contain the two sets $\left(\mathrm{A}_{\mathrm{ck}}\right.$ and $\left.\mathrm{D}_{\mathrm{ck}}\right)$.

The global specifications are added to the resulting automata in order to obtain to different distributed controllers.

An extract of a distributed controller is shown in figure 5 .

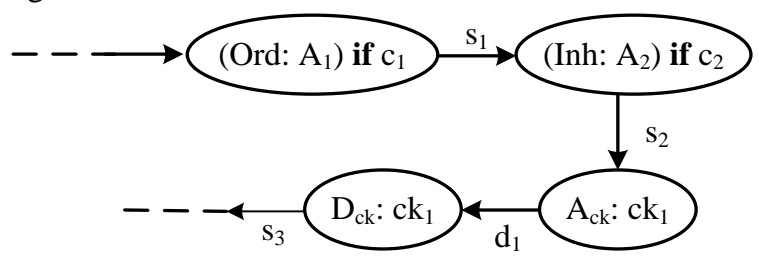

Figure 5 : Extract of distributed controller

For an implementation purpose, the distributed controllers and the reconfiguration specifications are interpreted under a grafcet language. A method of this interpretation is given in (Tahiri et al. 2018) and (Qamsane, Tajer, and Philippot 2016). 


\section{RESULTS AND DISCUSSION}

The two approaches are applied to an MS (figure 6-b) in order to reveal and evince the effectiveness of the two contributions.

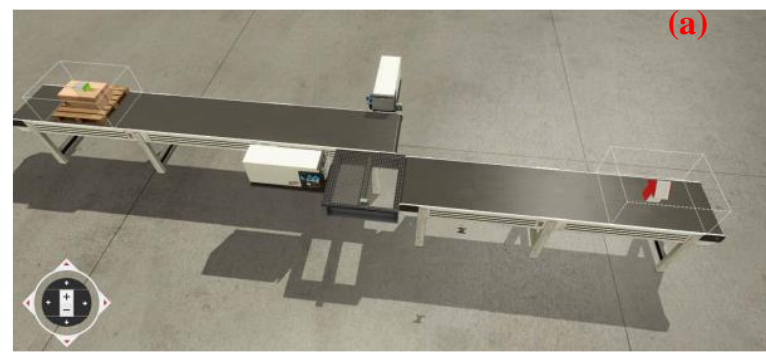

(b)

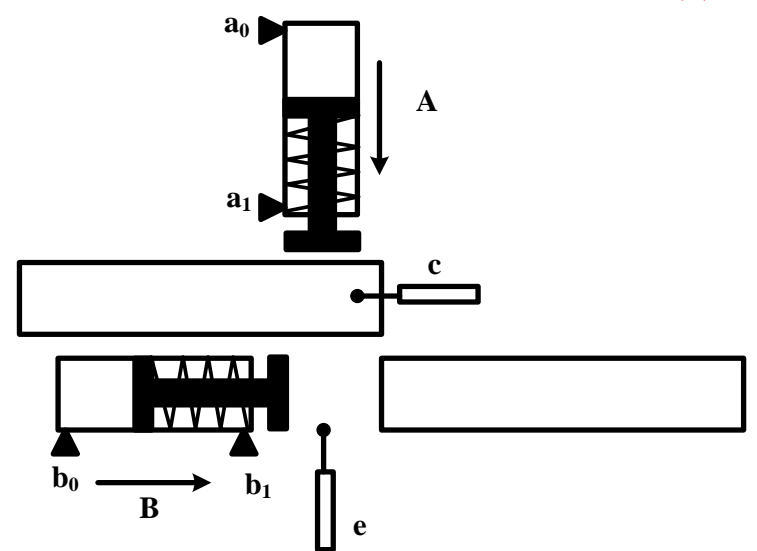

Figure 6 : The studied manufacturing system

This system is built using 3D FACTORY I/O simulator (figure 6-a) (https://factoryio.com/). The choice of this simulator is based in the fact that it gives us the possibility to create our own system while allowing a generation of different faults for either actuators or sensors.

The studied example consists in two pushers A and $B$ presented by two monostable single effect cylinders with their associated limit sensors $(\{a 0, a 1\}$ for $A$ and $\{\mathrm{b} 0, \mathrm{~b} 1\}$ for B). Two conveyor belts to transport boxes in front of $\mathrm{A}$, and to evacuate boxes to the stock. Two position sensors: $\mathrm{c}$ (resp. e) to detect boxes in front of A (resp. B). And finally, a start push button (dcy).

In this paper, we study the behavior of pushers $A$ and $\mathrm{B}$ and we ignore the two conveyor belts. For a distributed structure, the PE modelling is achieved according to the model presented in section (2.2.1). For each pusher we determine the normal and faulty behaviors (figure 7) and (figure8).

The models are realized by the help of SUPREMICA software. A falling edge refers in models to "down" and a rising edge refers to "up". In case of a0 fault detection, the sensor deactivation is replaced by the clock $\mathrm{ck} 1$ and the activation by the clock ck2. It is the same for a1 (clock ck3 for a1 activation and clock ck4 for a1 deactivation), for b0 (clock ck6 for b0 activation and clock ck5 for b0 deactivation) and b1 (clock ck7 for b1 activation and clock ck8 for b1 deactivation)
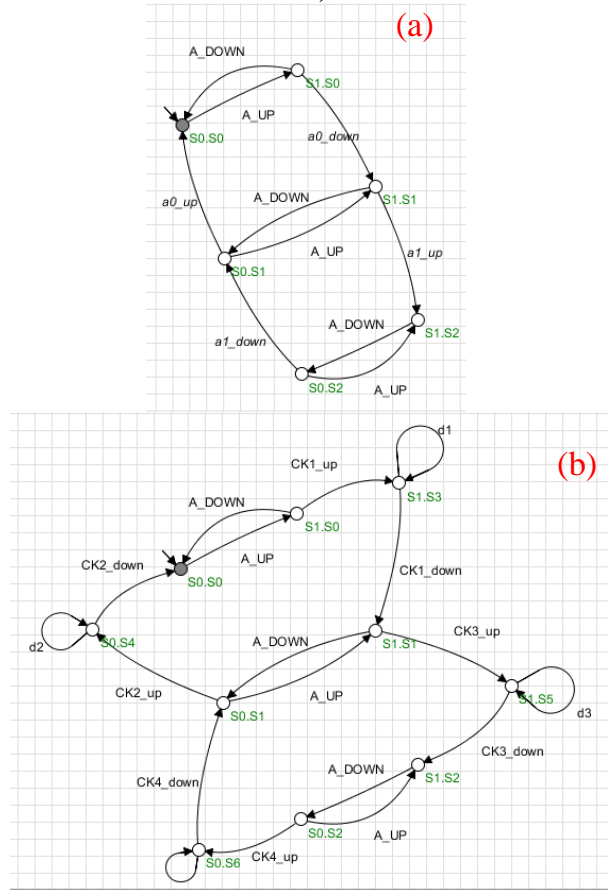

Figure $7:$ : (a) normal and (b) faulty behaviors of pusher A

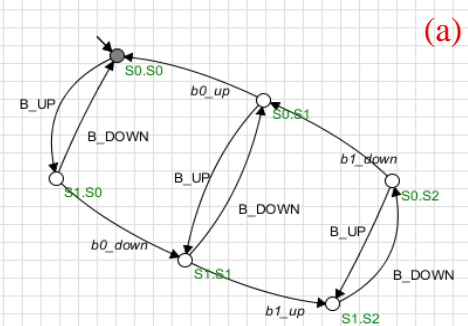

(a)

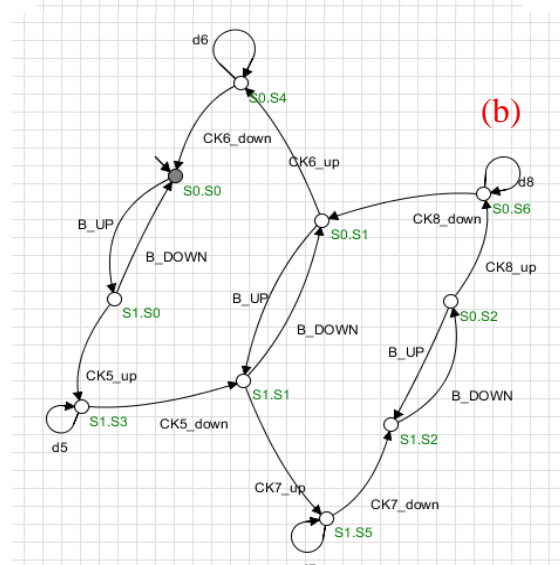

Figure 8 : (a) normal and (b) faulty behaviors of pusher $B$ 
While the centralized approach consists in defining the two global models of normal and faulty behavior. To obtain the normal plant modelling, the two normal models of pushers $\mathrm{A}$ and $\mathrm{B}$ are synchronized. The resulting automaton is given in figure 9 .

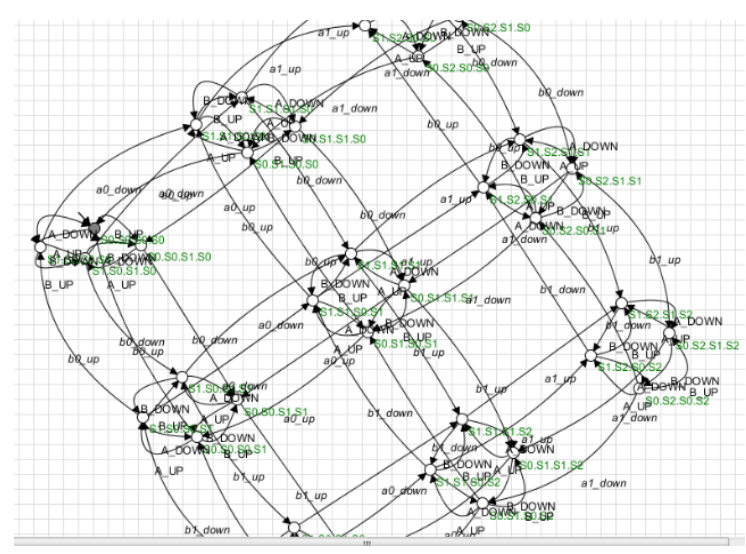

Figure 9 : Extract of normal behavior modelling of A and B

In the same way, we obtain the faulty behavior of $A$ and $B$ (figure 10).

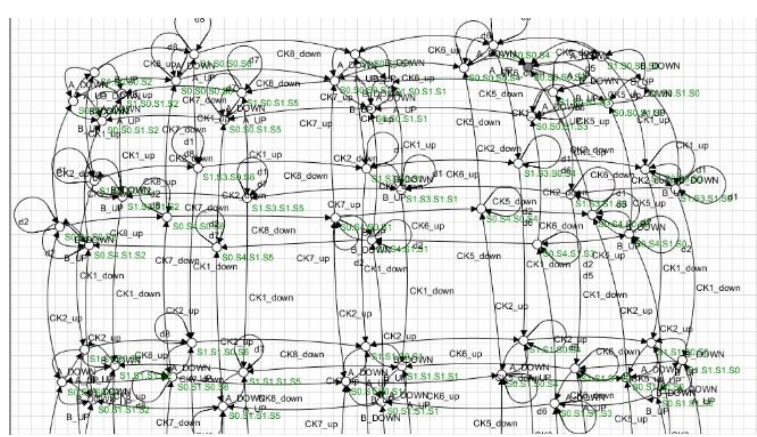

Figure 10 : Extract of faulty behaviour modelling of A and B

The normal behavior model is constituted by 36 states and 120 transitions. While the faulty behavior model is constituted by 100 states and 360 transitions. In this stage of the centralized framework design we observe the high number of states compared to the distributed approach.

The safety constraint of this MS is defined as follows: Do not send the exit orders of both cylinders $\mathrm{A}$ and $\mathrm{B}$ at the same time.

It is possible to define as liveness constraints the following specifications:

* Allowing the exit order of a pusher can only be realized if the cylinder is in a return position $(\mathrm{a} 0 / \mathrm{b} 0)$.
* The exit order of cylinder B can only be performed after the output of cylinder A.

Applying these different specifications in different stages of the control reconfiguration design for both contributions allows us to compare the two approaches in different stages too as shown in table 1 .

Table 1 : Comparative table of the two proposed approaches

\begin{tabular}{|c|c|c|c|c|c|}
\hline & \multicolumn{2}{|c|}{ Centralized app } & \multicolumn{3}{|c|}{ Distributed app } \\
\hline & States & Trs & & States & Trs \\
\hline \multirow[t]{2}{*}{$\mathrm{PO}_{\mathrm{N}}$} & \multirow[t]{2}{*}{36} & \multirow[t]{2}{*}{120} & $\mathrm{PE}_{\mathrm{NA}}$ & 6 & 10 \\
\hline & & & $\mathrm{PE}_{\mathrm{NB}}$ & 10 & 18 \\
\hline \multirow[t]{2}{*}{$\mathrm{PO}_{\mathrm{F}}$} & \multirow[t]{2}{*}{100} & \multirow[t]{2}{*}{360} & $\mathrm{PE}_{\mathrm{FA}}$ & 6 & 10 \\
\hline & & & $\mathrm{PE}_{\mathrm{FB}}$ & 10 & 18 \\
\hline \multirow[t]{2}{*}{$\operatorname{Sup}_{N}$} & \multirow[t]{2}{*}{27} & \multirow[t]{2}{*}{72} & Sup $_{\mathrm{NA}}$ & 6 & 10 \\
\hline & & & Sup $_{N B}$ & 10 & 18 \\
\hline \multirow[t]{2}{*}{$\operatorname{Sup}_{F}$} & \multirow[t]{2}{*}{72} & \multirow[t]{2}{*}{240} & Sup $_{\mathrm{FA}}$ & 6 & 10 \\
\hline & & & Sup $_{\mathrm{FA}}$ & 10 & 18 \\
\hline \multirow[t]{2}{*}{$\mathrm{Ctrl}_{\mathrm{N}}$} & \multirow[t]{2}{*}{27} & \multirow[t]{2}{*}{46} & $\mathrm{Ctrl}_{\text {LNA }}$ & 6 & 6 \\
\hline & & & $\mathrm{Ctrl}_{\mathrm{LNB}}$ & 10 & 14 \\
\hline \multirow[t]{2}{*}{$\mathrm{Ctrl}_{\mathrm{F}}$} & \multirow[t]{2}{*}{75} & \multirow[t]{2}{*}{191} & $\mathrm{Ctrl}_{\mathrm{LFA}}$ & 6 & 6 \\
\hline & & & $\mathrm{Ctrl}_{\mathrm{LFB}}$ & 10 & 14 \\
\hline \multirow[t]{4}{*}{$\mathrm{Ctrl}_{\mathrm{NF}}$} & \multirow[t]{4}{*}{675} & \multirow[t]{4}{*}{2521} & $\mathrm{Ctrl}_{\mathrm{DNA}}$ & 4 & 4 \\
\hline & & & $\mathrm{Ctrl}_{\mathrm{DNA}}$ & 4 & 4 \\
\hline & & & $\mathrm{Ctrl}_{\mathrm{DFA}}$ & 4 & 4 \\
\hline & & & $\mathrm{Ctrl}_{\mathrm{DFB}}$ & 4 & 4 \\
\hline \multirow{6}{*}{$\begin{array}{l}\text { Ctrl } \\
\text { reconf }\end{array}$} & \multirow[t]{6}{*}{172800} & \multirow[t]{6}{*}{52800} & $\mathrm{G}_{\mathrm{NA}}$ & 5 & 5 \\
\hline & & & $\mathrm{G}_{\mathrm{NB}}$ & 6 & 7 \\
\hline & & & $\mathrm{G}_{\mathrm{FA}}$ & 5 & 5 \\
\hline & & & $\mathrm{G}_{\mathrm{FB}}$ & 6 & 7 \\
\hline & & & $\mathrm{G}_{\mathrm{RA}}$ & 7 & 8 \\
\hline & & & $\mathrm{G}_{\mathrm{RB}}$ & 7 & 8 \\
\hline
\end{tabular}

Trs refers to the number of transitions.

$\mathrm{G}_{\mathrm{Ni}}$ refers to the grafcet corresponding to the normal distributed controller of $\mathrm{A}$ and $\mathrm{B}$.

$\mathrm{G}_{\mathrm{Ri}}$ refers to the reconfiguration specification to switch from a normal behavior to the faulty one of A (figure 11) and B or the contrary.

By analysing the table above, we deduce that the centralized approach for a control reconfiguration presents a combinatorial explosion. This is due to the use of the classic SCT in one hand. And in the other hand to the centralized structure, the second drawback is the ability to implement the resulting models. In fact, it is to complicate to interpret the resulting exploded models into a language of PLC programming. Moreover, despite that the MS proposed in this paper is a simple system constituted of two pushers, the corresponding reconfigured controller is given under a large size of states and transitions, which proves that obtaining the one corresponding to a complex system 
is a difficult task. Hence, the distributed approach solved the issues related to the first contribution.

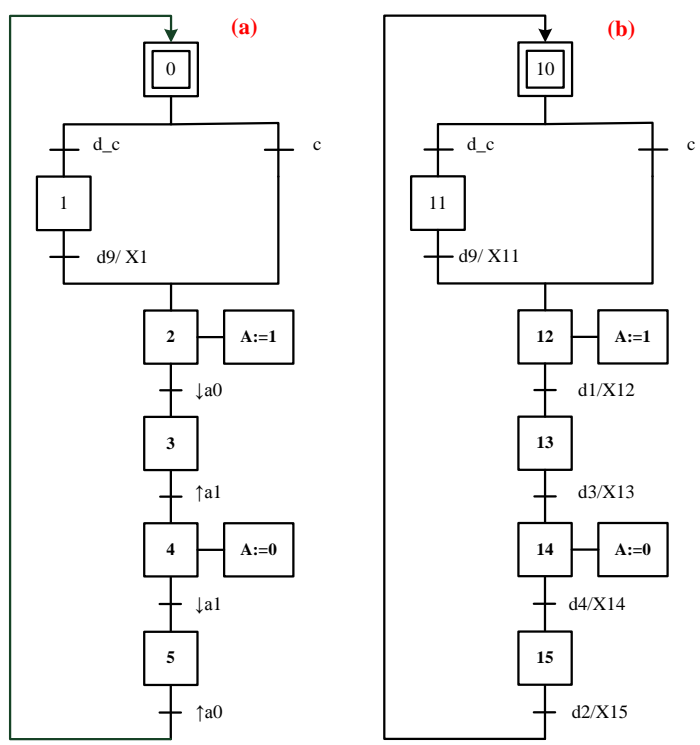

Figure 11 : (a) GNA and (b) GFA Grafcets

\section{CONCLUSIONS}

Responding to the operational safety issues in the field of systems' control, the implementation of formal methods is necessary. In this context, it is important to monitor the MS and to offer an alternative solution to maintain the production. Thus, a control reconfiguration of MS is required. For this aim, this paper has presented two new frameworks, the first one is based on a centralized control which we proved its low performance by an application on a transfer system. The second one is focused on a distributed control which comes to face out the problems related to the centralized approach. The key advantage of a distributed control reconfiguration approach is the use of distributed control that in the one hand avoid the combinatorial explosion recurrent in the centralized, approaches. On the other hand, it allows the reconfiguration of the only faulty $\mathrm{PE}$ without reconfiguring all the system's control. In addition, to replace the faulty sensor events by timed events that ensure the same behavior avoid the use of redundant element.

Our perspectives include the verification of the timed synthesis control proposed for the faulty or reconfigured mode. Also, we intend to develop the axis of reconfiguration of DES. In fact, a controller can be reconfigured due to a system's configurations change or to the specifications change according to the operator request. Feedback information for the operator on the faulty sensor repair can be taken into account. Therefore, this information will allow the switch from faulty behavior to the normal one. This could give some insights to be applied on a real MS (http://www.univ-reims.fr/meserp/cellflex-.0/cellflex4.0,9503,27026.html ) existing in our laboratory to improve the proposed work in future researchs.

\section{REFERENCES}

Akesson, K., M. Fabian, H. Flordal, and R. Malik. 2006. "Supremica - An Integrated Environment for Verification, Synthesis and Simulation of Discrete Event Systems." In 2006 8th International Workshop on Discrete Event Systems, 384-85. https://doi.org/10.1109/WODES.2006.38240 1.

Blanke, Mogens, Michel Kinnaert, Jan Lunze, and Marcel Staroswiecki. 2016. "Introduction to Diagnosis and Fault-Tolerant Control." In Diagnosis and Fault-Tolerant Control, 1-35. Springer, Berlin, Heidelberg. https://doi.org/10.1007/978-3-662-479438 . 1 .

Bordoloi, Sanjeev K., William W. Cooper, and Hirofumi Matsuo. 1999. "Flexibility, Adaptability, and Efficiency in Manufacturing Systems." Production and Operations Management 8 (2): 133-50. https://doi.org/10.1111/j.19375956.1999.tb00366.x.

Cassandras, Christos G, and Stéphane Lafortune. 2008. Introduction to Discrete Event Systems. Second Edition. New York. //www.springer.com/us/book/978038733332 8.

Hélouët, Loïc, Hervé Marchand, Blaise Genest, and Thomas Gazagnaire. 2014. "Diagnosis from Scenarios." Discrete Event Dynamic Systems $24 \quad$ (4): 353-415 https://doi.org/10.1007/s10626-013-0158-2.

Koren, Y., U. Heisel, F. Jovane, T. Moriwaki, G. Pritschow, G. Ulsoy, and H. Van Brussel. 1999. "Reconfigurable Manufacturing Systems." CIRP Annals 48 (2): 527-40. https://doi.org/10.1016/S00078506(07)63232-6.

Koren, Yoram, and Moshe Shpitalni. 2010. "Design of Reconfigurable Manufacturing Systems." Journal of Manufacturing Systems 29 (4): 
$130-41$. https://doi.org/10.1016/j.jmsy.2011.01.001.

Kul'ba, V., L. Busk Kofoed, D. Kononov, and O. Zaikin. 2016. "Scenario Research of Complex Manufacturing Systems' Vulnerability." IFAC-PapersOnLine, 8th IFAC Conference on Manufacturing Modelling, Management and Control MIM 2016, $49 \quad$ (12): $372-77$. https://doi.org/10.1016/j.ifacol.2016.07.633.

Philippot, A., and V. Carré-Ménétrier. 2011. "Methodology to Obtain Local Discrete Diagnosers: Submission for Special Session on Diagnosis of DES: Application on a Benchmark." In 2011 3rd International Workshop on Dependable Control of Discrete Systems, 47-52. https://doi.org/10.1109/DCDS.2011.597031 7.

Philippot, Alexandre. 2006. "Contribution Au Diagnostic Décentralisé Des Systèmes à Événements Discrets: Application Aux Systèmes Manufacturiers." Reims, France: Reims champagne Ardenne University.

Qamsane, Yassine, Abdelouahed Tajer, and Alexandre Philippot. 2016. "A Synthesis Approach to Distributed Supervisory Control Design for Manufacturing Systems with Grafcet Implementation." International Journal of Production Research, September. http://tandfonline.com/doi/abs/10.1080/0020 7543.2016.1235804.

Ramadge, P. J. G., and W. M. Wonham. 1989. "The Control of Discrete Event Systems." Proceedings of the IEEE 77 (1): 81-98. https://doi.org/10.1109/5.21072.

Rawat, Govind Singh, Ashutosh Gupta, and Chandan Juneja. 2018. "Productivity Measurement of Manufacturing System." Materials Today: Proceedings, International Conference on Processing of Materials, Minerals and Energy (July 29th - 30th) 2016, Ongole, Andhra Pradesh, India, 5 (1, Part 1): 1483-89. https://doi.org/10.1016/j.matpr.2017.11.237.

Reniers, G. 2017. "On the Future of Safety in the Manufacturing Industry." Procedia Manufacturing, Manufacturing Engineering Society International Conference 2017, MESIC 2017, 28-30 June 2017, Vigo (Pontevedra), Spain, 13 (January): 1292-96. https://doi.org/10.1016/j.promfg.2017.09.05 7.
Tahiri, Imane, Alexandre Philippot, Véronique CarréMénétrier, and Abdelouahed Tajer. 2018. "Timed Synthesis Approach for TolerantFault Control of Discrete Event Systems (DES)." In . marrakech-Morocco.

2019. "Time-Based Estimator for Control Reconfiguration of Discrete Event Systems (DES)." In . Paris-France.

Terkaj, Walter, Tullio Tolio, and Anna Valente. 2009.

"A Review on Manufacturing Flexibility." In Design of Flexible Production Systems: Methodologies and Tools, edited by Tullio Tolio, 41-61. Berlin, Heidelberg: Springer Berlin Heidelberg. https://doi.org/10.1007/978-3-540-854142_3.

Tuptuk, Nilufer, and Stephen Hailes. 2018. "Security of Smart Manufacturing Systems." Journal of Manufacturing Systems 47 (April): 93-106. https://doi.org/10.1016/j.jmsy.2018.04.007. 